\title{
Familial juvenile nephronophthisis, Jeune's syndrome, and associated disorders
}

\author{
M D C DONALDSON, A A WARNER, R S TROMPETER, G B HAYCOCK, \\ AND C CHANTLER \\ Evelina Children's Department, Guy's Hospital, London and Department of Radiology, \\ Peterborough General Hospital
}

SUMMARY Fourteen patients with familial juvenile nephronophthisis are described, eight of whom displayed one or more additional disorders. One boy with short limbed dwarfism and an abnormal chest was considered to have Jeune's syndrome; review of the published reports supports the view that nephronophthisis is the principal cause of renal failure in this disorder. Another patient with renal failure and retinitis pigmentosa at presentation developed progressive neurological and neuromuscular impairment leading to the discovery of ragged red fibre disease (mitochondrial cytopathy). Cardiomyopathy was present in this and one other patient. Tapeto-retinal degeneration, hepatic fibrosis, cerebellar ataxia, and oculomotor apraxia were among the other disorders encountered. Three patients presented in extremis with acute heart failure and irreversible oligo-anuria and this complication developed in another child who was already known to have nephronophthisis. Awareness of this disease and its associations is important for early diagnosis and appropriate management.

Familial juvenile nephronophthisis, first described in $1951,{ }^{1}$ is a chronic disease characterised clinically by polyuria, growth failure, and invariable progression to renal failure during childhood. ${ }^{2}$ In the early stages of the disease there may be little or no morphological abnormality of the kidneys but later medullary cysts may form, while biopsy shows noticeable tubular atrophy, severe interstitial damage, and secondary glomerular obsolescence. ${ }^{2} 3$ The condition is inherited as an autosomal recessive and there may be a family history of consanguinity. ${ }^{2} 3$

In recent years various abnormalities affecting other systems have been found in association with familial juvenile nephronophthisis. These include skeletal abnormalities,${ }^{4-7}$ hepatic fibrosis, ${ }^{8-10}$ tapetoretinal degeneration, ${ }^{11-15}$ cerebellar ataxia, ${ }^{4} 61015$ and mental retardation. ${ }^{1912} 15$ The condition has also been found in association with ragged red fibre disease (mitochondrial cytopathy), a disease complex in which neuromuscular involvement is a predominant feature. ${ }^{16}$

Although renal involvement in Jeune's syndrome (asphyxiating thoracic dystrophy) is well described, ${ }^{17-22}$ a direct link with familial juvenile nephronophthisis is not widely recognised. Similarly, the bony abnormalities associated with the latter disorder have not been linked with Jeune's syndrome, except on one occasion. ${ }^{23}$

We report on 14 patients with familial juvenile nephronophthisis seen at Guy's Hospital since 1971, eight of whom had additional disorders. The series includes a child with an abnormal chest and short limbed dwarfism who presented with acute circulatory overload and in whom a retrospective diagnosis of Jeune's syndrome was made. The link between familial juvenile nephronophthisis and Jeune's synrome is discussed, and the published reports on the renal lesion in Jeune's syndrome are reviewed. We also describe an association between familial juvenile nephronophthisis and cardiomyopathy in two patients, one of whom had mitochondrial cytopathy.

\section{Patients}

Table 1 gives the relevant clinical data on the 14 patients with familial juvenile nephronophthisis. The diagnosis was established by percutaneous or open renal biopsy in all cases. Histological requirements for diagnosis included the presence of diffuse tubulo-interstitial damage with tubular atrophy and moderate round cell infiltration together with a variable degree of glomerular sclerosis and fibrosis. 
Familial juvenile nephronophthisis, Jeune's syndrome, and associated disorders

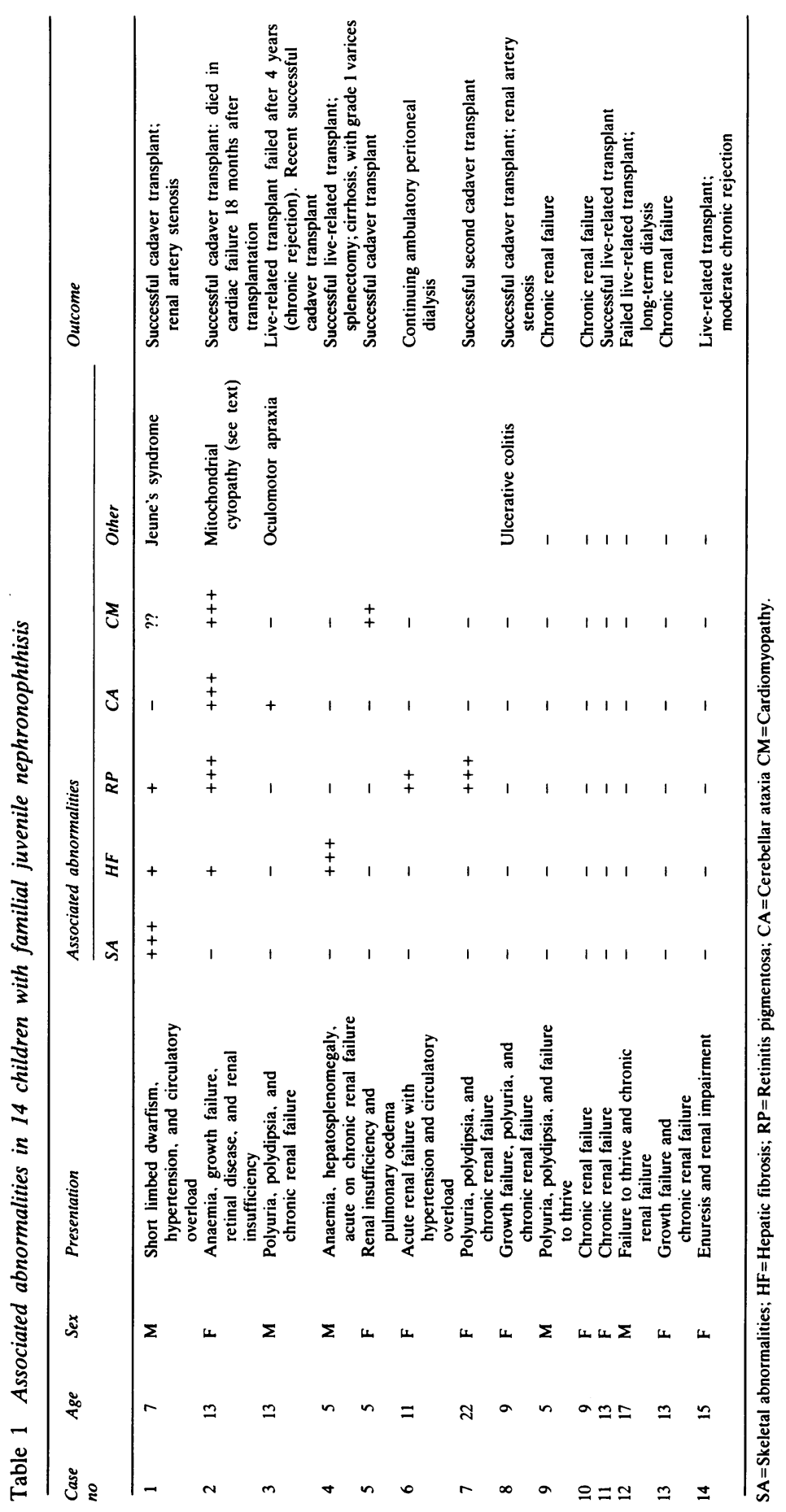


The presence of medullary cysts was not a diagnostic requirement especially as these are most unlikely to be detected on a biopsy. ${ }^{3}$ Two patients (cases 10 and 11) are siblings while case 7 had a brother with this disorder and retinitis pigmentosa who died age 10 years. The parents of case 5 are from Pakistan, and cases 10 and 11 are Turkish Cypriot; all the other patients are of British extraction. Eight of the 14 patients had one or more additional disorders and five of the more complex case histories are given in detail.

Case 1. This child was noted to have an oddlyshaped chest from birth but there was no respiratory difficulty and it was not until his second year that short stature became apparent. Detailed radiological investigation at this time showed a dyschondroplasia of indeterminate type. He then presented aged 6 years with a six week history of progressive oedema, oliguria, and cough; nocturia had been present since he was 2 years old. He was severely hypertensive (initial blood pressure $210 / 180 \mathrm{~mm} \mathrm{Hg}$ ) with gross circulatory overload and pulmonary oedema and irreversible oligo-anuria.

Investigation showed no anaemia, urinary obstruction, or vesico-ureteric reflux; renal ultrasound showed small kidneys with poor cortico-calyceal differentiation but no medullary cysts. Percutaneous renal biopsy (Fig. 1) showed hypertrophy of arteries and arterioles consistent with hypertension; appreciable tubular atrophy, interstitial fibrosis, and lymphocytic infiltrate; and many glomeruli were either sclerotic or showing periglomerular fibrosis. The appearances were consistent with familial juvenile nephronophthisis.

Liver biopsy was performed because of persisting

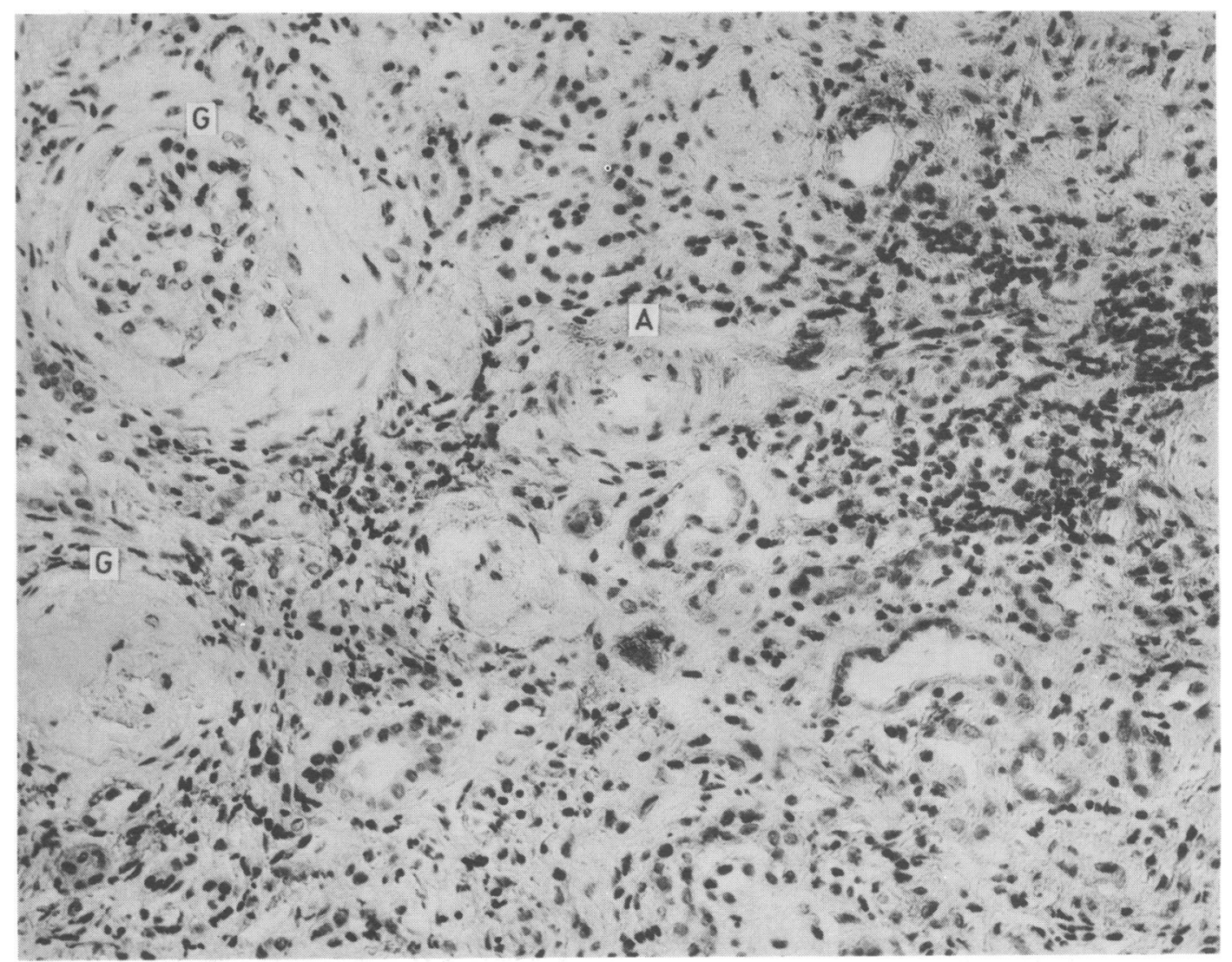

Fig. 1 Renal cortex from patient in case 1 showing one glomerulus $(G)$ obsolescent, and another with periglomerular fibrosis. There is a thickened arteriole $(A)$, extensive loss of tubules, and a patchy lymphocytic infiltrate. $(H$ and $E \times 250)$. 
hepatomegaly and showed a mild patchy portal tract fibrosis with bile duct proliferation, consistent with mild hepatic fibrosis. Fundoscopy showed pigment speckling in the periphery with no rise in activity on the electroretinogram during dark adaptation suggestive of rod degeneration, but this latter abnormality resolved after successful transplantation. The heart size remained large after the hypertension and circulatory overload had resolved and the echocardiogram showed a poorly contracting left ventricle with dyskenesis. Three months after transplantation the charges were still evident but less noticeable.

Hypertension has subsequently recurred and the aetiology of the cardiomyopathy remains uncertain. Muscle biopsy was carried out to exclude mitochondrial cytopathy, and was normal.

The patient's general appearance is shown in Fig. 2. Unusual features apart from extreme short stature (-4SD) include an elongated and cylindrical chest with sternal prominence, inframammary concavity, and costal flaring giving a bell shaped appearance; short limbs affecting the proximal

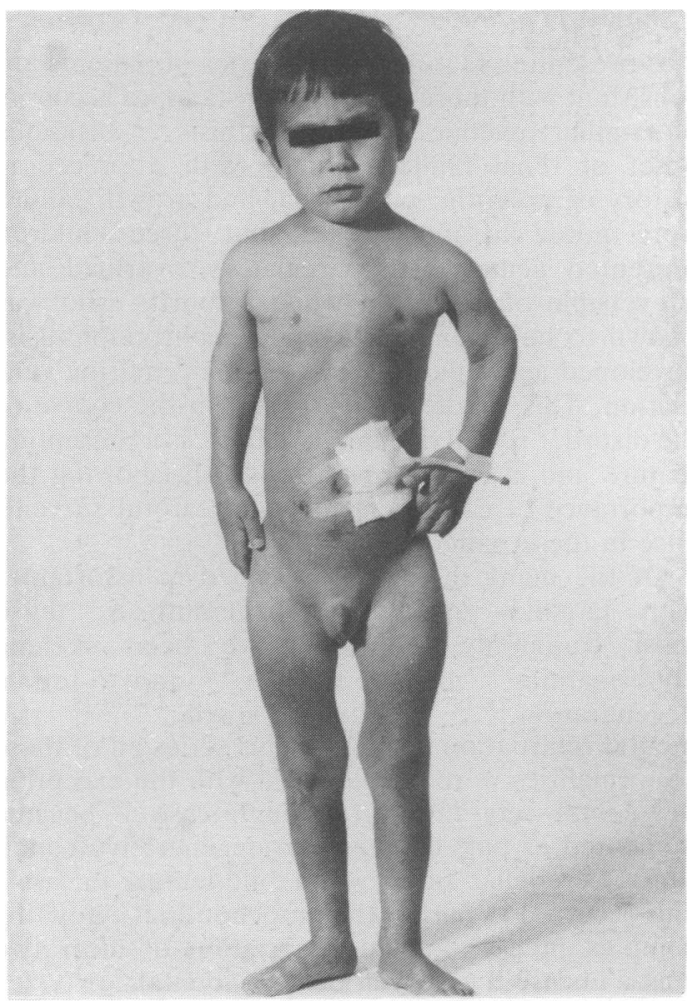

Fig. 2 Case 1, showing abnormal chest shape, short upper limbs especially proximally, and bowing of the thighs. Tenchkoff peritoneal dialysis catheter in situ. bones particularly; bowing of thighs, and short stubby fingers.

Radiographs taken at 15 months and 6 years of age showed similar abnormalities with more noticeable metaphysial changes latterly. In the chest there was a decrease in antero-posterior diameter with irregularity of the rib ends. Hand radiographs showed short bones and cone shaped epiphyses. There was squaring of the iliac bones with reduced acetabular angles and medial spurs (Fig. 3). The long bones showed shortening, most marked proximally. The scapulae were small and there were metaphysial irregularities of the distal humeri while the proximal femora showed metaphysial irregularity with streaky areas of sclerosis and translucency (Fig. 3). The skull and spine were normal. Both the external and radiological features were consistent 'with Jeune's syndrome.

Case 2. This child presented with failure to thrive at 8 months and subsequently developed non-specific anaemia. Retinitis pigmentosa was diagnosed when she was 5 years old, and by 8 years she was in chronic renal failure with severe growth failure. Renal biopsy showed severe tubular atrophy with occasional cystic dilatation, global sclerosis of some glomeruli, and increased mesangial matrix in others. The appearances were consistent with familial juvenile nephronophthisis. Eighteen months later the child received a cadaver transplant but by this time she had become ataxic with behaviour problems, recurrent convulsions associated with hypocalcaemia and unrecordable parathormone concentrations, and a grossly abnormal electroencephalogram. The graft functioned well but the child's health pursued a downward course and she developed deafness, worsening ataxia, cataracts, diabetes mellitus, ophthalmoplegia, and muscle

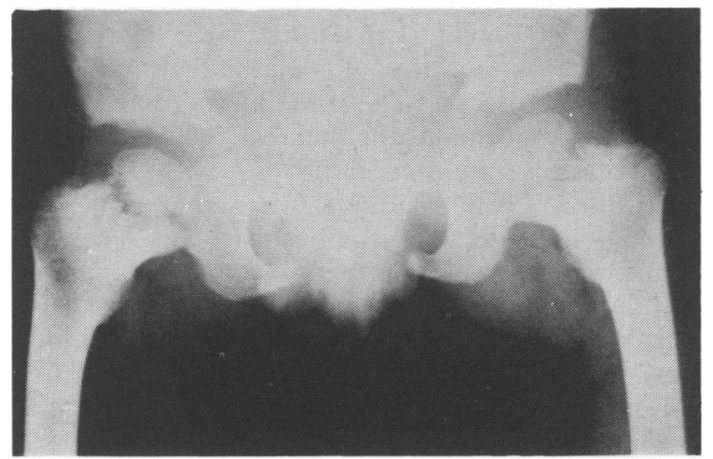

Fig. 3 Case 1, pelvic radiograph showing metaphysial dysplasia of proximal femora and reduced acetabular angles. 
wasting. Muscle biopsy was performed, electron microscopy of which showed the characteristic changes of ragged red fibre disease (mitochondrial cytopathy). Computed tomography of the head showed cerebral and cerebellar atrophy. Fifteen months after transplantation she developed cardiac failure, the echocardiogram showing very poor left ventricular contractility, and she died one month later. Necropsy showed atrophic kidneys with no medullary cysts, relatively well preserved glomeruli, but gross tubular atrophy; minor non-specific changes in the transplanted kidney; atrophy of the pancreatic islets; morphologically normal parathyroid glands; and the dilated heart with pale myocardium.

Case 3. This boy was noted to shake his head when fixing on an object at 4 months of age and 3 years later a diagnosis of cerebellar ataxia and Cogan's oculomotor apraxia was made. Polyuria, polydipsia, and short stature were noted at 6 years and he was found to be in chronic renal failure. Open renal biopsy showed pinpoint cortical cysts and histology was consistent with familial juvenile nephronophthisis. Two years later he required dialysis, and after undergoing host nephrectomy for hypertension he received a live donor graft. He is currently well after a second graft. His neurological symptoms are minimal and muscle biopsy has not been performed.

Case 4. This patient was found to have an iron deficiency anaemia when he was 2 years old and shortly after this hepatosplenomegaly was noted. Percutaneous cholangiogram showed a normal biliary system, while liver biopsy showed bile duct proliferation with mild portal inflammation. At this time the plasma creatinine value was $65 \mu \mathrm{mol} / \mathrm{l}$. He was admitted to hospital six months later with a four day history of dyspnoea and was found to be severely hypertensive (blood pressure 240/120 $\mathrm{mm} \mathrm{Hg}$ ) with anaemia (haemoglobin $5.9 \mathrm{~g} / \mathrm{dl}$ ) and a plasma creatinine value of $500 \mu \mathrm{mol} / \mathrm{l}$. Renal biopsy showed sclerosis of $50 \%$ of the glomeruli examined but little abnormality in the rest, while there was severe diffuse interstitial fibrosis with round cell infiltration. The histology was compatible with familial juvenile nephronophthisis. He received a transplant from his mother which has functioned well. Hypersplenism, severe enough to limit the use of azathioprine, became an increasing problem, however, and when he was 8 years old splenectomy was performed. At operation grade I varices and a cirrhotic liver were noted.

Case 5. This child was noted to have a poor appetite, polydipsia, polyuria, and nocturia from 18 months of age. At 4 years short stature and severe anaemia had developed and investigations showed advanced chronic renal failure. Renal biopsy showed changes consistent with familial juvenile nephronophthisis. Four months later, she was admitted to hospital with sudden onset of severe breathlessness after a three day history of cough. There were clinical signs of severe circulatory overload with pulmonary oedema but peripheral oedema was only slight, and blood pressure was $120 / 70 \mathrm{~mm} \mathrm{Hg}$. A chest radiograph showed cardiomegaly and pulmonary oedema. After a short period of peritoneal dialysis and ventilation, the signs of circulatory overload regressed but oliguria persisted, the heart remained large, and the echocardiogram repeatedly showed poor myocardial contractility. Muscle biopsy showed no evidence of mitochondrial cytopathy and there was no clinical sign of retinal or hepatic disease.

She received a cadaver transplant which has functioned well, and over a two year period her heart size has returned to normal.

\section{Discussion}

The presenting features in our series of patients are consistent with those described in standard accounts of familial juvenile nephronophthisis. ${ }^{2}{ }^{3}$ Insidious onset of renal failure, usually with a preceding history of polyuria, polydipsia, and growth failure were noted in most cases, but three children presented acutely with circulatory overload and irreversible oligo-anuria, while a fourth, who was known to have familial juvenile nephronophthisis, developed acute pulmonary oedema requiring ventilation. This sudden development in the course of the disorder is well documented both as a presenting feature and a cause of sudden death, showing the importance of early diagnosis and careful surveillance in these patients.

Of the many disorders described in association with familial juvenile nephronophthisis, those most commonly reported have been skeletal abnormalities, ${ }^{4-7}$ hepatic fibrosis, ${ }^{8-10}$ tapeto-retinal degeneration, ${ }^{11-15}$ cerebellar ataxia, ${ }^{4} 61015$ and mental retardation. ${ }^{1912} 15$ In this series all of these abnormalities were encountered with the exception of mental retardation (although case 2 became demented as part of her neurodegenerative condition). Cerebellar ataxia was a mild feature in case 3 and occurred as part of the mitochondrial cytopathy complex in case 2. The association of ulcerative colitis in case 8 may well be coincidental.

A wide spectrum of skeletal abnormalities have been reported in patients with familial juvenile nephronophthisis. In the siblings described by 
Mainzer, ${ }^{4}$ cone shaped epiphyses were found, together with metaphysial dysplasia of the proximal femora in the younger subject, while radiology on the patients of Bodaghi $^{7}$ showed additional abnormalities of the iliac bones and acetabulum.

Shah $^{23}$ described three patients, all of whom died from the disorder, who displayed short limbs and thoraco-pelvic-phalangeal dystrophy characteristic of Jeune's syndrome. In one of these patients, who was described originally by Chakera ${ }^{5}$ and subsequently by Robins et $a l,{ }^{24}$ the diagnosis of Jeune's syndrome was made retrospectively. The concept of partial expression of the skeletal features in Jeune's syndrome is supported by Shokeir, ${ }^{18}$ who observed minor chest and hand abnormalities in three relatives of a family with affected subjects, and by Oberklaid et al, ${ }^{22}$ who described a 15 year old boy, two of whose siblings had some respiratory difficulty at birth, persistently small chests, and iliac abnormalities in one. The skeletal abnormalities in case 1 seem fully consistent with Jeune's syndrome. although the pelvic changes are not pronounced.

In 1955 Jeune $^{25}$ described two siblings who died in infancy from respiratory failure due to thoracic dystrophy. Associated features were short stubby hands with cone shaped epiphyses and trident shaped iliac bones, while subsequent development of short limbed dwarfism with metaphysial dysplasia has since been recognised. Since Jeune's original description survival beyond infancy has been well documented, the thoracic abnormality showing relative improvement, with an increased tendency towards chest infections but no late deaths from respiratory failure. The development of chronic renal failure, however, has become an increasingly recognised complication in subjects escaping death from respiratory failure in infancy.

Table 2 summarises the clinical features and renal pathology of patients from seven series of case reports on Jeune's syndrome. The cases can be broadly classified into two groups: babies dying soon after birth or in infancy owing to respiratory failure. with necropsy evidence of renal disease; and older children in whom covert renal disease was found or in whom chronic renal failure occurred. In the first group varying degrees of tubular dilatation sometimes resulting in cortical cysts were frequently found, while Bernstein ${ }^{10}$ describes an infant with cystic dysplasia and another with diffuse cystic disease. In the second group all patients showed tubular atrophy, interstitial fibrosis and infiltration. and glomerular sclerosis. Four of the authors mention the similarity to nephronophthisis, although Gruskin $^{21}$ found the degree of glomerular disease to be in apparent excess of the tubular damage. Hepatic fibrosis, usually mild, was frequently noted. while four of Gruskin's patients and Edelson's ${ }^{21}$ case showed retinal pigmentation.

Although the renal lesion in Jeune's syndrome seems to be heterogeneous, with various forms of dysplasia predominating in infancy and early childhood, we believe the progressive lesion found in older subjects to be indistinguishable from that of familial juvenile nephronophthisis. This concept is based not only on consideration of the renal histology which is basically that of a diffuse tubulointerstitial nephropathy with no pathognomonic feature, but also on other features common to both disease complexes such as hepatic fibrosis, retinal pigmentation, and autosomal recessive inheritance. This intriguing overlap is not necessarily restricted to familial juvenile nephronophthisis and the Jeune syndrome. Tapeto-retinal degeneration, polydactyly (a recognised feature in Jeune's syndrome), autosomal recessive inheritance, and a renal lesion which may closely resemble familial juvenile nephronophthisis or medullary cystic disease are all found in the Laurence-Moon-Bardet-Biedl syndrome. ${ }^{26}$ Further systematic study of patients with these poorly understood disorders is required to clarify the links between them.

We also suggest that the skeletal abnormalities described in familial juvenile nephronophthisis might be considered as variable expressions of the Jeune syndrome and that subjects presenting with this type of short limbed dwarfism be kept under close renal surveillance. The disorder seems a common complication in patients with Jeune's syndrome who survive infancy, although there is one report of an adult with Jeune's syndrome, ${ }^{27}$ while the 15 year old patient in Oberklaid's series was well with no evidence of renal disease. 22 By contrast skeletal abnormalities in children presenting with familial juvenile nephronophthisis seem to constitute one of the less common disease associations.

The spectrum of severity in hepatic fibrosis accompanying this disorder is evident in our series; case 1 displaying only slight hepatomegaly with mild portal fibrosis on biopsy whereas case 3 has severe hepatic fibrosis with portal hypertension. Although case 3 required dialysis before his third birthday, his hepatic histology is dissimilar to that seen in a series of patients recently described ( $R$ Habib personal communication) all of whom had renal enlargement, histology compatible with familial juvenile nephronophthisis, and end stage renal failure before 2 years of age.

The tapeto-retinal degeneration described first by Senior ${ }^{11}$ and then Loken ${ }^{12}$ in association with familial juvenile nephronophthisis encompasses optic atrophy with blindness dating from infancy ${ }^{1+}$ and pigmentary retinopathy with variable progression and 


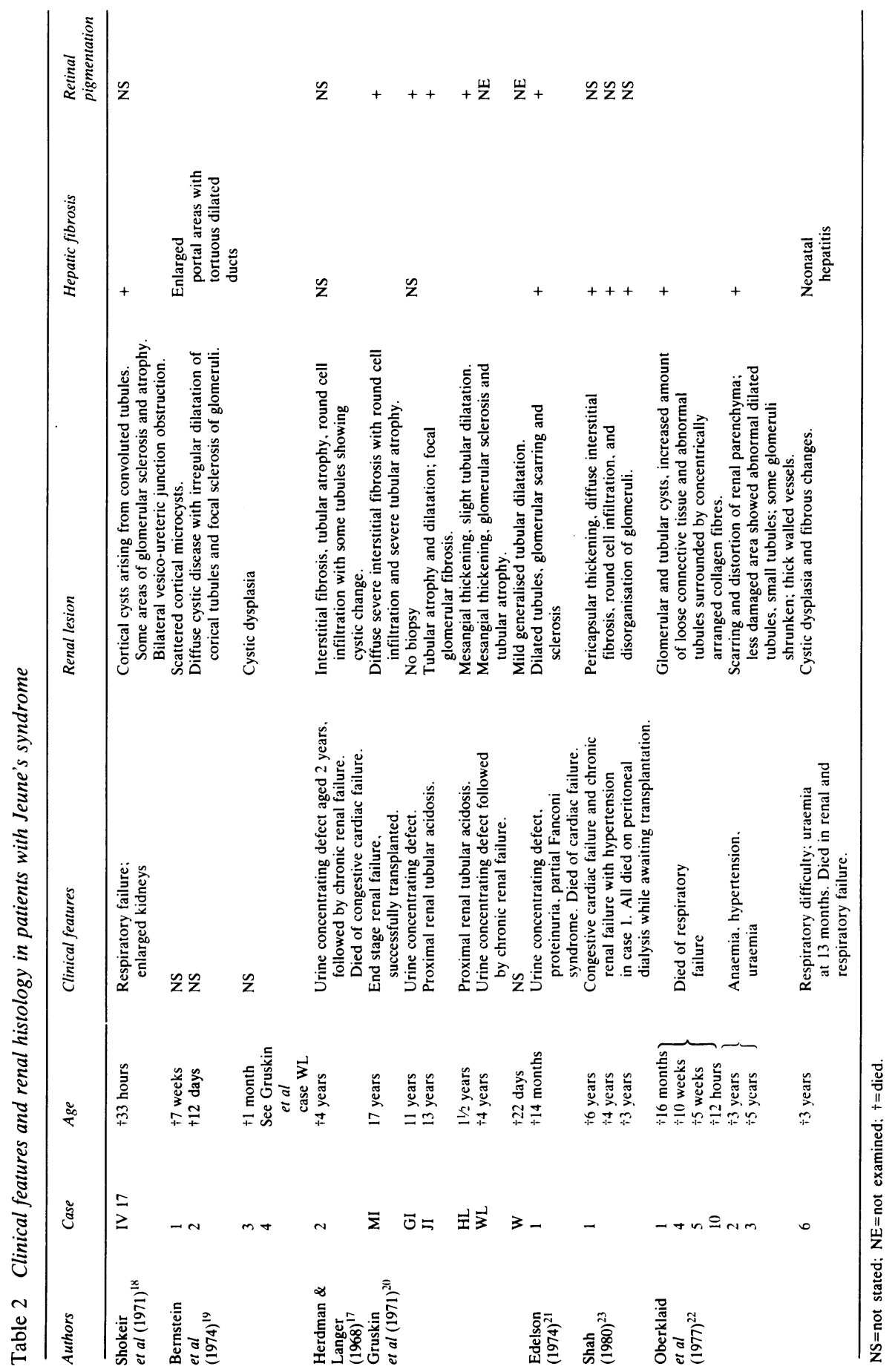


handicap. In this series case 7 has tunnel vision but reasonable acuity, case 6 has severe myopia but no visual defect, and case 1 has asymptomatic pigment speckling of the retinae. Case 2 was found to have pigmentary retinopathy in the early stages of her illness but subsequently developed other features which led to the diagnosis of mitochondrial cytopathy.

The association between familial juvenile nephronophthisis and mitochondrial cytopathy-a disease complex featuring ophthalmoplegia, ptosis, pigmentary retinopathy, cerebellar ataxia, deafness, weakness, and neurodegeneration was briefly mentioned in the series of Egger et al. ${ }^{16}$ In fact the child mentioned in an addendum to Egger's paper is case 2 in our series. The authors also described three other children with progressive renal disease, one of whom died age 3 years in renal failure. Renal biopsy from this patient showed severe diffuse segmental glomerulosclerosis and tubular atrophy. The other patients were not biopsied but both had renal failure and in one the presenting features included polydipsia, polyuria, constipation, and a Fanconi syndrome. The outcome in patients with mitochondrial cytopathy is poor and we would advise muscle biopsy in patients with familial juvenile nephronophthisis and neuromuscular symptoms.

Cardiomyopathy was found in case 2 in the context of mitochondrial cytopathy but occurred as an isolated feature in case 5, whose muscle biopsy was normal. Cardiomyopathy has not been reported previously in association with this disorder but, as mentioned above, the sudden development of acute congestive heart failure in familial juvenile nephronophthisis is well recognised. While the circulatory overload in such cases may be purely secondary to oliguric renal failure, an unrecognised cardiomyopathy could be a contributory factor in some intances.

The coexistence of familial juvenile nephronophthisis and the various skeletal, hepatic, retinal, and neuromuscular disorders described in this paper is probably more common than is generally appreciated. A wider awareness of the association would promote earlier investigation and diagnosis of children at high risk, avoiding the late and potentially catastrophic presentation seen in several of the children in this series.

We thank Dr R B Hartley for his comments on the renal histology of case 1, Dr R Habib for reviewing the hepatic and renal histology of case 4, and Valerie Hayne for typing the manuscript.

\author{
References \\ ${ }^{1}$ Fanconi G, Hanhost E, Albertini A von, Lichlinger E,
}

Dolivo G, Prader A. Die familiare juvenile nephronophthise (die Idiopathinche Parenchymatose Schrumpfniere). Helv Paediatr Acta 1951;6:1-49.

2 Bernstein J, Gardner KD. Familial juvenile nephronophthisismedullary cystic disease. In: Edelmann CM, ed. Pediatric renal disease. Vol II. Boston: Little, Brown and Company, 1978: $580-6$.

${ }^{3}$ Waldherr R, Lennert T, Weber H-P, Fodisch HJ, Scharer K. The nephronophthisis complex. Virchows Arch [Pathol Anat] 1982;394:235-54.

${ }^{4}$ Mainzer F, Saldino RM, Ozonoff MB, Minagi H. Familial nephropathy associated with retinitis pigmentosa, cerebellar ataxia and skeletal abnormalities. Am J Med 1970;49:556-62.

${ }^{5}$ Chakera TMH. Peripheral dysostosis associated with juvenile nephronophthisis. Br J Radiol 1975;48:765-6.

6 Popovic-Rolovic M, Calic-Perisic G, Bunjevacki G, Negovanovic $D$. Juvenile nephronophthisis associated with retinal pigmentary dystrophy, cerebellar ataxia, and skeletal abnormalities. Arch Dis Child 1976;51:801-3.

7 Bodaghi E, Zaman T, Kheradpir MH. Familial nephropathy associated with congenital liver fibrosis, degenerative retinitis and cone-shaped epiphysis. Int J Pediatr Nephrol 1980;1:153-6.

${ }^{8}$ Boichis H, Passwell J, David R, Miller H. Congenital hepatic fibrosis and nephronophthisis. $Q J$ Med 1973;42:221-9.

9 Proesman W, Damme B Van, Macken J. Nephronophthisis and tapeto-retinal degeneration associated with liver fibrosis. Clin Nephrol 1975;3:160-4.

${ }^{10}$ Dietrich E, Straub E. Familial juvenile nephronophthisis with hepatic fibrosis and neurocutaneous dysplasia. Helv Paediatr Acta 1980;35:261-7.

1 Senior B, Friedmann AI, Braudo JL. Juvenile familial nephropathy with tapeto-retinal degeneration. Am J Ophthalmol 1961;52:625-33.

12 Loken AC, Hanssen O, Halvorsen S, Jolster NJ. Hereditary renal dysplasia and blindness. Acta Paediatr Scand 1961;50: $177-84$.

13 Schimke RN. Hereditary renal-retinal dysplasia. Ann Intern Med 1969;70:735-44.

14 Roizenblatt J, Cunha LAP. Leber's congenital amaurosis with associated nephronophthisis. J Pediatr Ophthalmol Strabismus 1980;17:154-8.

${ }^{15}$ Fontaine J-L, Boulesteix J, Saraux H, et al. Nephropathie tubulo-interstitielle de l'enfant avec degenerescence tapetoretinienne. Arch Fr Pediatr 1970;27:459-70.

${ }^{16}$ Egger J, Lake BD, Wilson J. Mitochondrial cytopathy. A multisystem disorder with ragged red fibres on muscle biospy. Arch Dis Child 1981:56:741-52.

${ }^{17}$ Herdman RC, Langer LO. The thoracic asphyxiant dystrophy and renal disease. Am J Dis Child 1968;116:192-201.

${ }^{18}$ Shokeir MHK, Houston CS, Awen CF. Asphyxiating thoracic chondrodystrophy; association with renal disease and evidence for possible heterozygous expression. J Med Genet 1971;8: 107-12.

${ }^{19}$ Bernstein J, Brough AJ, McAdams AJ. The renal lesion in syndromes of multiple congenital malformations; cerebrohepatorenal syndrome; Jeune's asphyxiating thoracic dystrophy; tuberous sclerosis; Meckel syndrome. Birth Defects 1974;10: 35-43.

${ }^{20}$ Gruskin AB, Baluarte HG, Cote ML, Elfenbein IB. The renal disease of thoracic asphyxiant dystrophy. Birth Defects 1974; 10:44-50.

21 Edelson P, Spackman TJ, Belliveau RE, Mahoney MJ. A renal lesion in asphyxiating thoracic dysplasia. Birth Defects 1974;10:51-6.

22 Oberklaid F, Danks DM, Mayne V, Campbell P. Asphyxiating thoracic dysplasia. Arch Dis Child 1977;52:758-65.

${ }^{23}$ Shah KJ. Renal lesion in Jeune's syndrome. Br $J$ Radiol 1980;53:432-6. 
${ }^{24}$ Robins DG, French TA, Chakara TMH. Juvenile nephronophthisis associated with skeletal abnormalities and hepatic fibrosis. Arch Dis Child 1976;51:799-801.

25 Jeune M, Beraud C, Carron R. Dystrophie thoracique asphyxiante de caractere familial. Arch Fr Pediatr 1955; 12:886-91.

${ }^{26}$ Hurley RM, Dery P, Nogrady MB, Drummond KN. The renal lesion of the Laurence-Moon-Biedl syndrome. $J$ Pediatr $1975 ; 87: 206-9$.
${ }^{27}$ Friedman JM, Kaplan HG, Hall JG. The Jeune syndrome (asphyxiating thoracic dystrophy) in an adult. Am J Med 1975;59:857-62.

Correspondence to Dr M D C Donaldson, Royal Hospital for Sick Children, St Michael's Hill, Bristol.

Received 4 January 1985

\section{Editorial Committee}

Members of the Editorial Committee usually serve for five years, and in that time they referee many of the submitted original manuscripts. In addition they advise the Editors about policy, particularly in relation to their own areas of special interest and expertise. B E Clayton, J F T Glasgow, R J Levinsky, and A D Milner have retired from the Committee; we thank them for their loyal and efficient work on behalf of our journal. We welcome as new members of the Editorial Committee:

D P Addy

M J R Healy

J V Leonard

E R Moxon

M Silverman

M J Tarlow
Consultant Paediatrician, Dudley Road Hospital, Birmingham;

Professor of Medical Statistics, London School of Hygiene and Tropical Medicine;

Senior Lecturer, Institute of Child Health, London;

Professor of Paediatrics, University of Oxford;

Senior Lecturer, Department of Paediatrics and Neonatal Medicine, Royal Postgraduate Medical School, London;

Senior Lecturer, Department of Paediatrics and Child Health, East Birmingham Hospital. 